University of Nebraska - Lincoln

DigitalCommons@University of Nebraska - Lincoln

6-10-2020

\title{
Changing Grid Premiums and Discounts Due to Underlying Changes in the Fed Cattle Industry
}

Elliott James Dennis

University of Nebraska-Lincoln, elliott.dennis@unl.edu

Follow this and additional works at: https://digitalcommons.unl.edu/ageconfarmmgmt

Part of the Agribusiness Commons, Entrepreneurial and Small Business Operations Commons, Management Information Systems Commons, Other Business Commons, and the Other Economics Commons

Dennis, Elliott James, "Changing Grid Premiums and Discounts Due to Underlying Changes in the Fed Cattle Industry" (2020). Extension Farm and Ranch Management. 39.

https://digitalcommons.unl.edu/ageconfarmmgmt/39

This News Article is brought to you for free and open access by the Agricultural Economics Department at DigitalCommons@University of Nebraska - Lincoln. It has been accepted for inclusion in Extension Farm and Ranch Management by an authorized administrator of DigitalCommons@University of Nebraska - Lincoln. 


\section{Changing Grid Premiums and Discounts Due to Underlying Changes in the Fed Cattle Industry}

By:

Elliott Dennis

June 10, 2020

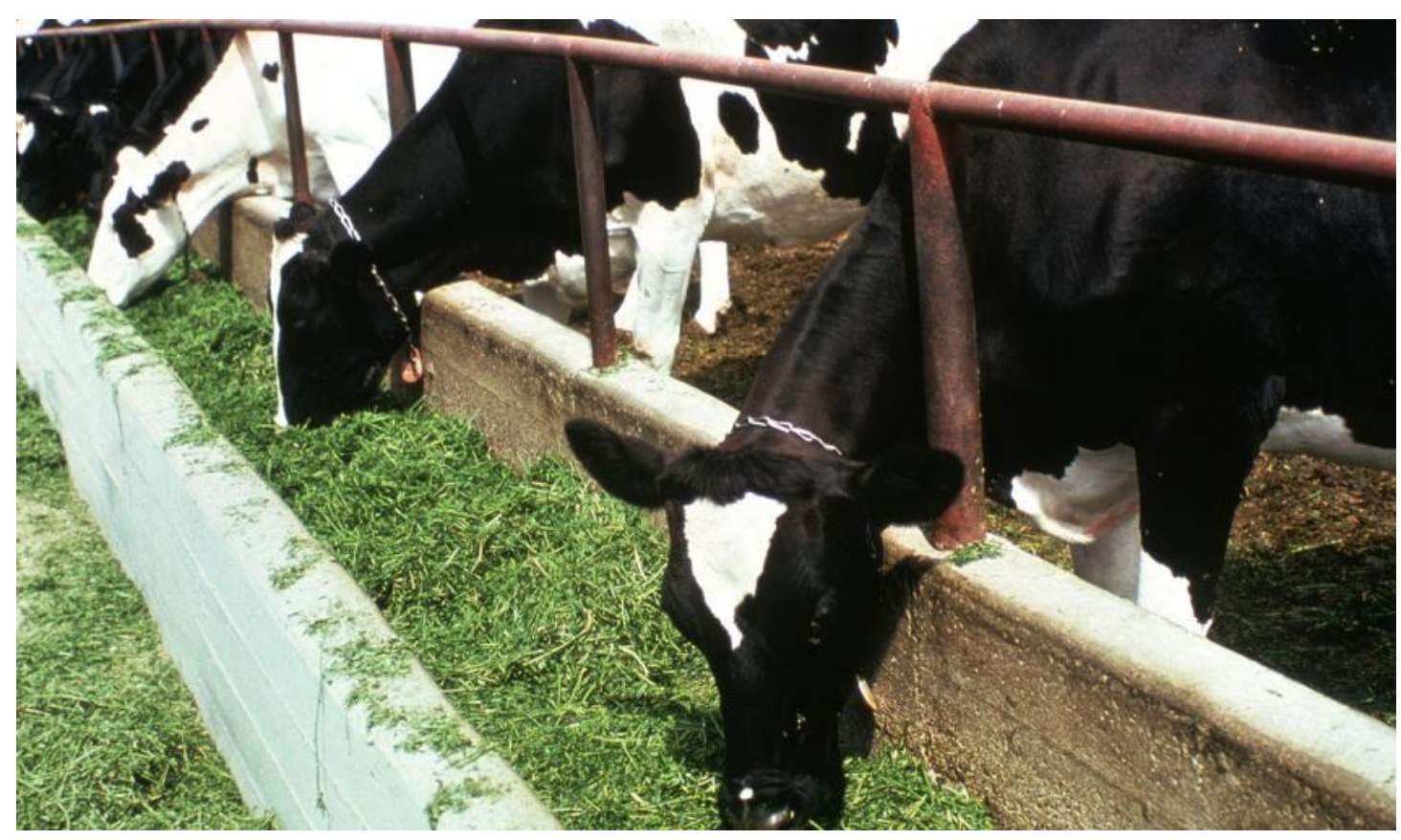

This article was originally published in the June 9, 2020 edition of In The Cattle Markets.

In recent weeks there has been increased attention given to the role of Alternative Marketing Arrangements, commonly referred to as AMA's, in the fed cattle market. The use of these AMA's varies greatly by region and some of the more common AMA's used include grid and formula pricing. AMA's pay producers premiums and discounts from a 'base price' based on a combination of the yield grade, quality grade, and weight of dressed cattle. It is common for the negotiated cash price to serve as the 'base price' for AMA's using the either the geographical region or the 5-market average. The decline in negotiated cash trade has varied by geographical region causing some market participants to wonder if the 'base price' truly reflects the local demand for cattle. For example, cattle formula priced in Texas using the 5-market average could, in certain weeks, be heavily weighted towards Nebraska and Iowa prices.

However, the current concern surrounding AMA's has more to do with lower cash prices received by producers due to market reactions to COVID-19 than the role of AMA's role in thinly traded markets. In an effort to effectively raise producer received prices, market 
participants have introduced a series of price and supply control proposals. The U.S. Senate, led by Senator Chuck Grassley (R-IA) and Senator Jon Tester (D-MT), have proposed a law that would mandate large-scale packers to procure a minimum of 50 percent of total cattle purchased in the cash market each week - commonly referred to as the '50-14' rule. The hope is that by increasing cash trade transactions it will solve issues with price discovery effectively increasing negotiated cash prices. Supply of fed cattle and demand for wholesale beef determines the price of fed cattle. In order to increase fed cattle prices, the '50-14' rule would either need to reduce the supply of fed cattle or increase the demand for wholesale beef. While the rule would increase negotiated cash transactions helping in price discovery in a given week, it is unlikely to affect the underlying fed cattle market supply and demand conditions to effectively increase cash price levels.

Two other efforts to increase cash transactions, in hopes of increasing cash prices, is 'bid-thegrid' through the Fed Cattle Exchange platform and the 'set aside' program (similar to the one used in Canada). Many details and questions still lack regarding the 'bid-the-grid' process and potential efficacy in increasing regional cash trade. Its aim is to increase prices by having each producer negotiate grid the starting base price. While this may help in price discovery (i.e. arriving at a transaction price for a given quality and quantity of a product at a given time and place) this method once again falls short of fundamentally changing price determination. The 'set aside' program aims to control the number of cattle that enter the market each week that can be processed. Producers would be paid a set amount per day to compensate for the cost of feeding. Who would be willing to pay for the program as well as program start and end dates is likewise uncertain. This may help reduce the backlog due to packing plant closures, cattle will be processed quickly as soon as food service demand increases.

So what has been happening to cattle transactions (i.e. negotiated cash, forward contract, formula, and negotiated grid) during COVID-19? Looking at all cattle in the U.S., formula transactions have largely been replaced by negotiated grid. For example, in April formula trade was $74 \%$ of total weekly transactions and negotiated grid was $4 \%$. In May formula trade fell to $48 \%$ and negotiated grid was $20 \%$. The past few weeks cattle sold on formula has steadily increased while cattle on the negotiated grid have decreased. There has been little change in the negotiated cash and forward contract trade, on average for the U.S., since January 1, 2020. As in most cases there were significant differences across geographical regions. Formula trade fell in the Texas-Oklahoma-New Mexico region but not below 5-year historical levels. This was offset by trade in the negotiated grid. Formula priced cattle fell from $95 \%$ of cattle priced in April to $30 \%$ in May. This was replaced entirely by negotiated grid priced cattle. In both the TexasOklahoma-New Mexico and Kansas region there was little movement in the negotiated price. Pricing in Nebraska has been somewhat more volatile. Negotiated cash fell a historic low of $2 \%$ of transactions in May and entirely offset by increased formula trade. Negotiated grid and forward contract transactions were historically constant.

Since negotiated cattle can be sold either live or dressed final cash payment is always determined by quantity (i.e. lbs. of animal/carcass) times negotiated price. Formula or grid priced cattle rely upon a base price plus discounts or premiums for cattle quality or characteristics. Premiums for quality are paid for carcasses grading Prime or Certified Angus Beef (CAB) or production practices such as 'All Natural' or 'Non Hormone Treated Cattle' (NHTC). Choice is the base 
quality grade and discounts are applied to carcasses grading select. Figure 1 plots the grid premiums and discounts for the 5-market average between 2018 and 2020. Since Jan 1, 2020 NHTC and 'All Natural' premiums have remained constant, CAB premiums have increased, Prime premiums have decreased, and Select discounts have increased. The difference between Choice and Select, commonly referred to as the Choice-Select spread, is largely consistent with historical patterns of widening during the first quarter. The deterioration in the premium for Prime and the sharp increase in CAB are abnormal. One reason for the deterioration in the premium for Prime product is likely due to the reduced demand for high end steaks at restaurants from quarantine restrictions accompanied by an increase in supply due to fed cattle being on feed longer as packing plant closed.

Grids or formulas also require cattle carcasses to be within a given weight range, generally between 600-900 lbs. on dressed basis. Cattle that fall outside of these limits are discounted. Cattle slaughter weight has increased as packing plants closed causing reduced packing capacity and cattle to be on feed longer than anticipated. For example, the dressed weight for steers and heifers has increased by about $10 \mathrm{lbs}$. at a time when dressed weight historically decreases. So how have weight discounts changed since January? Figure 2 plots the weight discounts for the 5market average from 2018-2020. Weight discounts were constant for all weights prior to January 1, 2020. After that, the discount for cattle carcasses over $1050 \mathrm{lbs}$. has decreased. In other words, packers discounted heavy carcasses less than in months and years prior. All other weight discounts have remained unchanged. Seen in the light of historical discounts, this change in grid pricing for heavy cattle is unprecedented. For context, cattle are usually harvested between 1200 $1350 \mathrm{lbs}$. on live weight basis. Given a $63 \%$ dressing percentage, cattle are weighing upwards of 1500 lbs. Assuming an ADG of 3 lbs. per day, cattle harvested were on feed approximately 1.5 to 2 months longer. This would align well with the timing of COVID-19 cases in packing plants.

The underlying makeup of cattle transactions the market is seeing, and previously discussed above, is likely more due to a change in the grid premiums and discounts than a fundamental shift in producer preference for the way cattle are transacted. As the grid premiums and discounts have changed, in some cases dramatically, more cattle have once again shifted away from negotiated grid towards formula. As the U.S. come out of the COVID-19 quarantine restrictions, it is likely that share of cattle transactions are likely to normalize to historical levels. Fed cattle cash prices are likely to increase as a result due to an improvement in domestic retail and food service beef and export beef demand. Current proposals to increase the number of cattle transacted through a particular channel is unlikely to affect beef demand derived from consumers and passed along the supply chain down to producers or alter the current supply of fed cattle ready for harvest. While their long-term implications are unknown, creating new transaction prices are unlikely do little to fundamentally change price determination, potentially causing increased costs and reducing profitability for the beef complex. Consistent with the economic theory of derived demand, the economic burden of these policies are likely to largely carried by the cow-calf industry. 


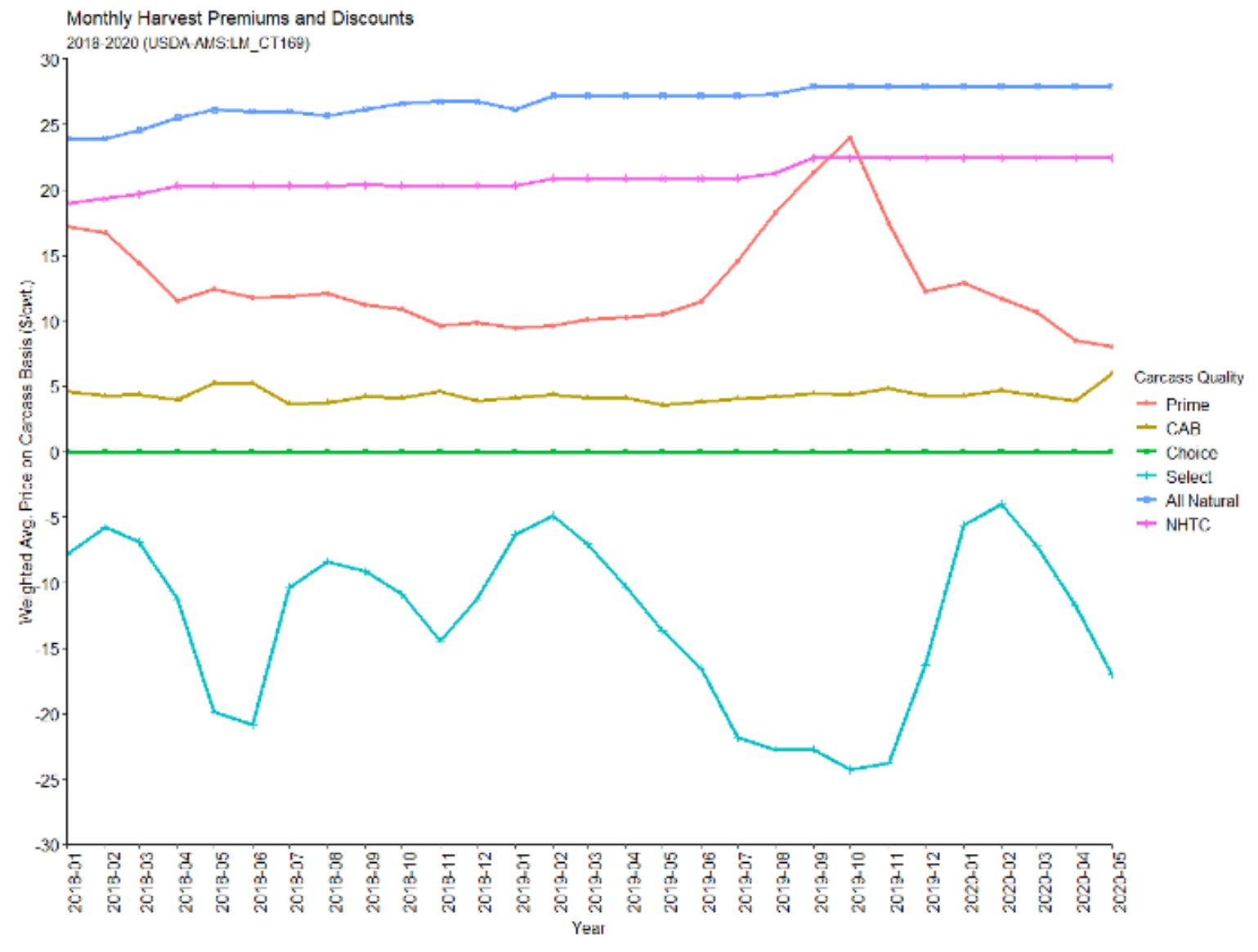

Figure 1. Monthly Harvest Premium and Discounts for Carcass Quality between 2018 and 2020: 5-market average (USDA-AMS:LM_CT169). 


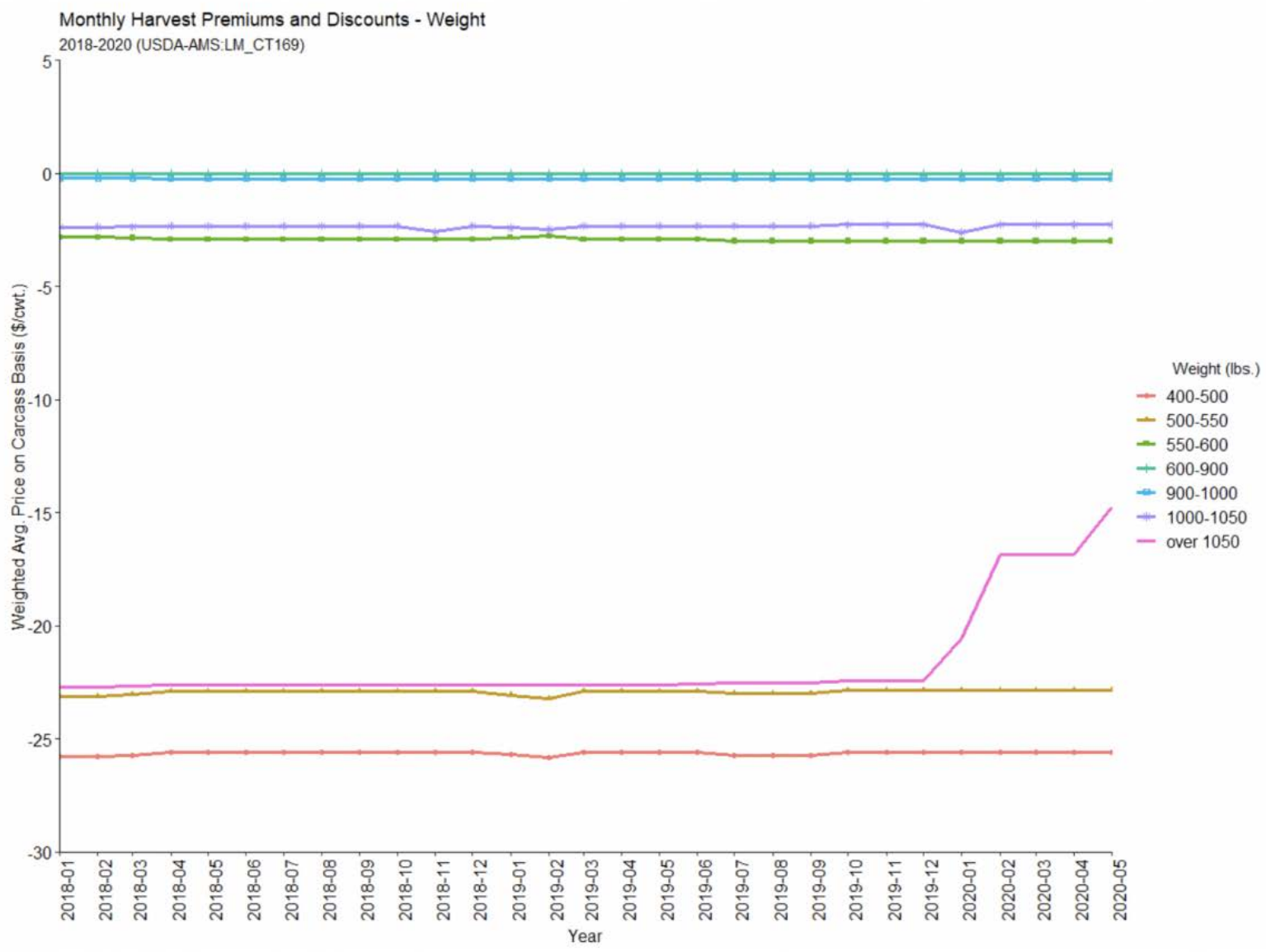

Figure 2. Monthly Harvest Premium and Discounts for Weight between 2018 and 2020: 5market average (USDA-AMS:LM_CT169).

Elliott Dennis

Assistant Professor and Livestock Marketing Economist

elliott.dennis@unl.edu

Department of Agricultural Economics 